\title{
THE ANALYSIS OF TOBACCO CONSUMPTION IN CROATIA - ARE WE SUCCESSFULLY FACING THE EPIDEMIC?
}

\author{
Ivan Padjen ${ }^{1}$, Marina Dabić ${ }^{2}$, Tatjana Glivetić ${ }^{3}$, Zrinka Biloglav, Dolores Biočina-Lukenda ${ }^{5}$, Josip Lukenda \\ ${ }^{1}$ Division of Clinical Immunology and Rheumatology, Department of Internal Medicine, University of Zagreb School of Medicine, University \\ Hospital Centre Zagreb, Zagreb, Croatia \\ ${ }^{2}$ University of Zagreb, Faculty of Economics and Business, Zagreb, Croatia \\ ${ }^{3}$ General Hospital Zabok, Zabok, Croatia \\ ${ }^{4}$ Andrija Stampar School of Public Health, Zagreb University School of Medicine, Zagreb, Croatia \\ ${ }^{5}$ Split University School of Medicine, Split, Croatia \\ ${ }^{6}$ University Hospital Centre Split, Split, Croatia
}

\begin{abstract}
SUMMARY
Tobacco is the largest cause of morbidity and mortality. The aim of this study is to analyse several health and economically related indicators of tobacco consumption: smoking prevalence, standardized death rates (SDRs) from lung cancer and the proportion of GDP spent on tobacco in Croatia and other transitional countries - the Czech Republic, Slovakia, Poland, Hungary, Slovenia, Romania, and Bulgaria. The overall smoking prevalence in Croatia decreased by $5.2 \%$ during $1994-2005$, more among females $(-9.9 \%)$ than males $(-0.3 \%)$. There is no significant difference in the smoking prevalence between Croatia (27.4\%) and other countries. However, 33.8\% of Croatian males smoked during 2002-2005, more than in Romania and the Czech Republic, and less than in Hungary and Poland. The prevalence of female smoking (21.7\%) in Croatia is similar to the female smoking prevalence in Poland, the Czech Republic, and Hungary, but male smoking is predominant in all countries. The proportion of smokers among youth is above $20 \%$ and it is the highest in the Czech Republic (29.7\%), followed by Hungary (26.7\%), Slovenia (24.9\%), Croatia $(24.1 \%)$, and Poland $(21.5 \%)$. The proportion of smokers among girls is higher than among boys in Slovenia, Hungary, the Czech Republic, and Croatia, contrary to Slovakia, Bulgaria, and Poland where boys smoke slightly more. There is no significant difference between the prevalence of smoking among girls in Croatia and Bulgaria, Poland, the Czech Republic, Hungary, Slovenia, and Slovakia. According to the SDR from lung cancer in males (70.3/100,000), Croatia is ranked high assuming the 3rd place, after Hungary (99.7) and Poland (72.0). With a SDR of 15.9/100,000 for females, Croatia is ranked slightly better - 5th place. Tobacco consumption continues to be a major public health problem in transitional countries. Croatia conducted several campaigns and programmes in the past. However, results reveal that current anti-tobacco strategies are ineffective in reducing the smoking prevalence among men and youth. Men do not smoke less than a decade ago and, despite the observed decline among women, increasing trends are observed among teenage girls. Croatia should apply a comprehensive approach that would include raising awareness of health risks, restriction of smoking in public places, higher taxing, implementing stricter bans on advertising and promotion of tobacco as well as supporting smoking cessation. This last measure is believed to bring about some results in the medium term in targeted population groups, provided that it is supported by all health professionals. Otherwise, we may expect progress at the population level in the field of social stigmatization of smoking and wider intolerance to second-hand smoke. The full impact of smoking on the population health is yet to be seen and in the future it will undoubtedly remain one of the major contributors to the poor public health situation in Croatia.
\end{abstract}

Key words: tobacco, Croatia, smoking prevalence, youth, lung cancer mortality

Address for correspondence: I. Padjen, M.S. Bolšića 19, 10000 Zagreb, Croatia. E-mail: ivan_padjen@yahoo.ca

\section{INTRODUCTION}

Tobacco is the largest cause of morbidity and mortality in Europe. It is the 2 nd major cause of death and the 4 th most common health risk factor in the world. If this situation remains unchanged, tobacco is likely to cause around 10 million deaths each year in the next decade (1). Even though there has been increasing awareness of the harmful effects of smoking in the European Union (EU), the proportion of smokers is still high - approximately one third of the European population smokes and 650,000 deaths per year are smoking-related. It is of concern that almost half of these deaths is registered in the population aged 35-69 years, which is well below the average life expectancy (2). Reduction of mortality and morbidity caused by this global pandemic is a public health priority. Only a comprehensive approach seems to be efficient. Thus, the EU anti-smoking strategy includes a wide spectrum of smoking prevention and cessation activities, such as health education measures, improved consumer information and assistance as well as restrictions on tobacco advertising and marketing (3-6). Numerous diseases are related to smoking; however, cardiovascular diseases, chronic obstructive pulmonary disease (COPD), and lung cancer have the greatest impact on mortality and disability. Croatia does not hold a favorable position regarding tobacco consumption and tobacco-related deaths. As much as $90 \%$ of 
lung cancer cases are tobacco related and Croatia is ranked 3rd in Europe after Poland and Hungary in respect of standardized death rates (SDRs) ascribed to lung cancer (70.3/100,000 for men and 15.9/100,000 for women) (7). These high death rates can to some extent be explained by a high proportion of adult smokers in the population, i.e., almost one third of males (33.8\%) and over one fifth of females (21.7\%). Nonetheless, the contribution of other factors, such as availability of screening programmes and quality of health care, should not be neglected. Recent data about tobacco use among young people (24.1\%) suggest that this addiction will remain a major public health issue in the nearby future (8). As an EU candidate country Croatia is trying to reduce the prevalence of tobacco use through implementation of stricter enforcement of new laws against smoking and, in general, prioritize anti-tobacco policy in the national health agenda. Besides the negative effect on the population health, tobacco consumption causes direct and indirect costs and represents a heavy economic burden for consumers on a daily basis. Research in this area in Croatia is limited, hence total tobacco related costs are hard to estimate. The aim of this paper is to present several indicators related to tobacco use: (i) the prevalence among adults and youth; (ii) the standardized death rates (SDRs) from lung cancer for the population 25-64 years of age, both as mortality indicators; and (iii) the proportion of gross domestic product (GDP) spent on tobacco products, as an economic burden indicator.

\section{MATERIALS AND METHODS}

This is a comparative study of seven EU Member States and Croatia, which is an EU candidate country. The selected EU countries include Member States which joined EU in 2004 and 2007 (Slovenia, Hungary, the Czech Republic, Slovakia, Poland, Bulgaria, and Romania). The Tobacco Control Database (http://data. euro.who.int/tobacco/) was searched in August 2009 and data were retrieved for the above mentioned countries. This database covers 41 indicators of tobacco use and control policies of 48 WHO European Member States grouped into five main areas: smoking prevalence, legislation, economics, smoking cessation, and general policy. Smoking prevalence among adults was obtained for the 1994-1998, 1999-2001 and 2002-2005 periods. Additionally, data on the smoking prevalence among youth were obtained for the 1997-2001 and 2002-2005 periods. It is noteworthy that the definition of adult and youth age groups depends on age ranges used in primary sources, e.g., national surveys, from which the data had been implemented into the Tobacco Control Database. These primary sources used different age ranges and methodologies. Retrieving data from the EUROSTAT database, we obtained proportions of gross domestic product (GDP) spent on tobacco products in the 2005-2008 period for the selected countries. Latest available SDRs from lung cancer for the working-age population (25-64 years) were obtained and presented according to gender from relevant WHO sources (4). Comparison between variables was made using the $\chi^{2}$ test in SPSS 17.0 (SPSS Inc., Chicago, Illinois, U.S.A.). We also used the $\chi^{2}$ test to estimate the smoking trend in Croatia (1994-2005) according to gender. We compared data on the prevalence of smoking (total, men, and women) for the period 2002-2005 between Croatia and other countries. Countries with missing data were excluded from the analysis.

\section{RESULTS}

\section{Prevalence of Smoking among Adults and Youth}

The total prevalence of smoking in Croatia decreased insignificantly by $5.2 \%$ during the $1994-2005$ period: from $32.6 \%$ in the $1994-1998$ to $30.3 \%$ in the $1999-2001$, and $27.4 \%$ in the $2002-2005$ period $\left(\chi^{2}=0.640 ; p=0.424\right)$ (data not shown). The decrease of female smoking by almost $10 \%(31.6 \%, 26.6 \%$ and $21.7 \%$, respectively) is the primary factor that contributed to this mildly negative trend. Conversely, the prevalence of smoking among males remained almost the same, with only a slight decrease from $34.1 \%$ to $33.8 \%$ (Fig. 1). The observed trends are not statistically significant $\left(\chi^{2}=2.500\right.$ and $\mathrm{p}=0.114$ for females, $\chi^{2}=0.002$ and $\mathrm{p}=0.964$ for males).

The total prevalence of smoking in Croatia (27.4\%) is not significantly different from the prevalence in Romania $\left(\chi^{2}=0.976\right.$; $\mathrm{p}=0.323)$, Poland $\left(\chi^{2}=0.507 ; \mathrm{p}=0.477\right)$, the Czech Republic $\left(\chi^{2}=0.103 ; p=0.748\right)$, Hungary $\left(\chi^{2}=0.964 ; p=0.326\right)$, and Slovenia $\left(\chi^{2}=0.009 ; p=0.924\right)$ (Fig. 2).

According to the latest available data (2002-2005), 33.8\% of Croatian males smoke. This proportion is higher in Hungary

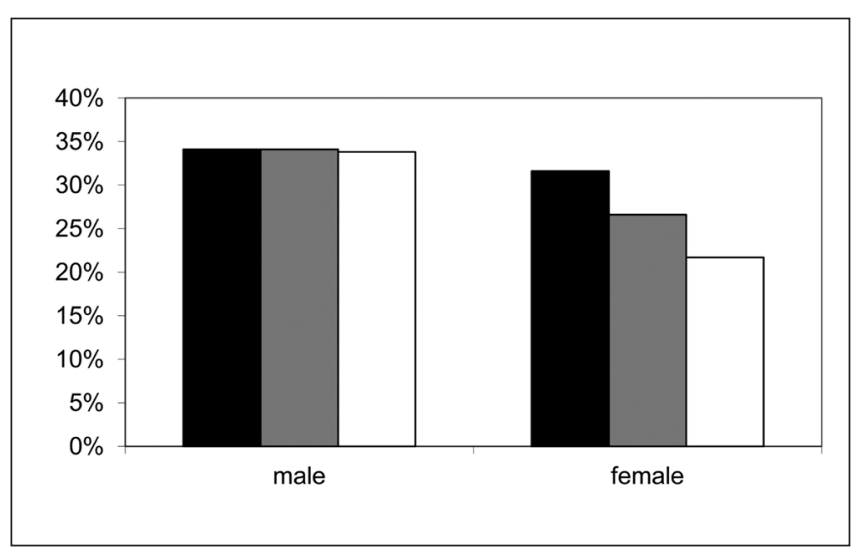

Fig. 1. The proportion of smokers in Croatia according to gender (1994-2005).

Legend: black: 1994-1998; grey: 1999-2001; white: 2002-2005

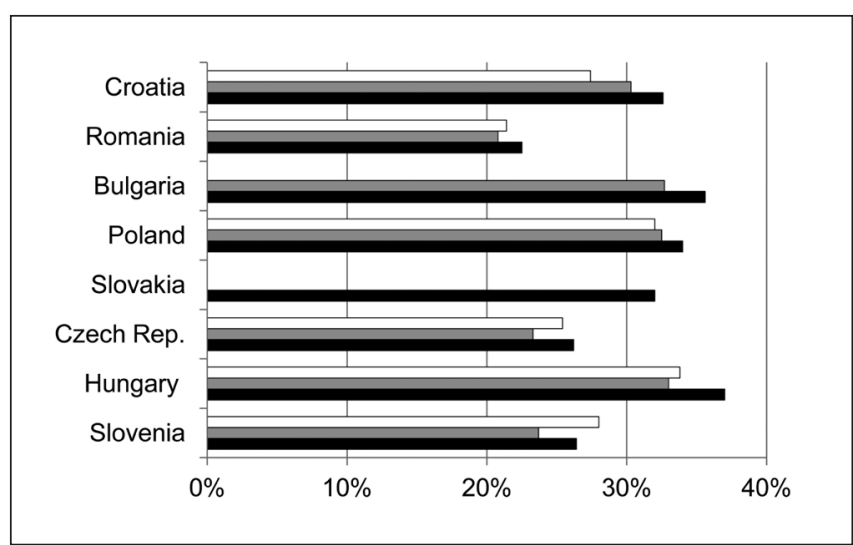

Fig 2. The proportion of smokers among adults in Croatia and other countries (1994-2005).

Legend: black: 1994-1998; grey: 1999-2001; white: 2002-2005

Data for Slovakia for 1999-2001 and 2002-2005, and Bulgaria for 2002-2005 are not available. 
Table 1. The proportion of smokers according to gender in Croatia and other countries (1994-2005)

\begin{tabular}{|l|c|c|c|c|c|c|}
\hline \multirow{2}{*}{} & \multicolumn{3}{|c|}{ Male } & \multicolumn{3}{c|}{ Female } \\
\cline { 2 - 7 } & $1994-1998$ & $1999-2001$ & $2002-2005$ & $1994-1998$ & $1999-2001$ & $2002-2005$ \\
\hline Slovenia & $33.20 \%$ & $28.00 \%$ & NA & $20.50 \%$ & $20.10 \%$ & NA \\
\hline Hungary & $46.00 \%$ & $40.60 \%$ & $40.50 \%$ & $28.00 \%$ & $26.30 \%$ & $27.80 \%$ \\
\hline Czech Republic & $32.80 \%$ & $26.40 \%$ & $31.10 \%$ & $20.20 \%$ & $20.40 \%$ & $20.10 \%$ \\
\hline Slovakia & $41.10 \%$ & NA & NA & $14.70 \%$ & NA & NA \\
\hline Poland & $44.00 \%$ & $42.00 \%$ & $38.00 \%$ & $24.00 \%$ & $23.00 \%$ & $25.60 \%$ \\
\hline Bulgaria & $49.20 \%$ & $43.80 \%$ & NA & $23.80 \%$ & $23.00 \%$ & NA \\
\hline Romania & $35.60 \%$ & $32.30 \%$ & $33.20 \%$ & $10.50 \%$ & $20.10 \%$ & $10.30 \%$ \\
\hline Croatia & $34.10 \%$ & $34.10 \%$ & $33.80 \%$ & $31.60 \%$ & $26.60 \%$ & $21.70 \%$ \\
\hline
\end{tabular}

NA - data not available

$(40.5 \%)$ and Poland $(38.0 \%)\left(\chi^{2}=0.961\right.$ and $p=0.327, \chi^{2}=0.383$ and $\mathrm{p}=0.536$ respectively), and lower in Romania (33.2\%) and the Czech Republic (31.1\%) $\left(\chi^{2}=0.008\right.$ and $p=0.928, \chi^{2}=0.166$ and $\mathrm{p}=0.683$ respectively), but without statistical significance. There is also no significant difference in the prevalence of female smoking between Croatia and Poland $\left(\chi^{2}=0.421 ; \mathrm{p}=0.516\right)$, the Czech Republic $\left(\chi^{2}=0.077 ; p=0.781\right)$ and Hungary $\left(\chi^{2}=0.999 ; p=0.318\right)$. Croatia is the only selected country with a decreasing trend of the total prevalence of smoking, both among males and females. As expected, all analysed countries have higher proportions of smokers among males and the male to female prevalence ratio is quite similar between Croatia (1.55), Poland (1.48), Hungary (1.46), and the Czech Republic (1.55). With ratio of 3.22, Romania is the only exception in this group (Table 1).

The proportion of smokers among youth is quite similar among observed countries and the total prevalence of smoking is higher than 20\% in each country. The Czech Republic is ranked first $(29.7 \%)$, followed by Hungary (26.7\%), Slovenia (24.9\%), Croatia (24.1\%), and Poland (21.5\%) (data not shown). Interestingly, according to recent 2002-2005 data, the proportion of smokers among girls is higher than among boys in the majority of selected countries: Slovenia $29.7 \%$ vs. $29.5 \%$, Hungary $28.8 \%$ vs. $28.2 \%$, the Czech Republic $30.6 \%$ vs. $28.7 \%$, and Croatia $24.9 \%$ vs. $23.2 \%$. An opposite pattern is observed in Slovakia and Bulgaria - boys smoke slightly more than girls: $31.1 \%$ vs. $28.1 \%$ in Slovakia and $28.7 \%$ vs. $26.4 \%$ in Bulgaria. The smoking prevalence among youth is lowest in Poland, where boys smoke more than girls, $26.3 \%$ vs. $17.0 \%$. The comparison of two periods, 1997-2001 and 2002-2005, reveals that an increasing trend of smoking prevalence is observed among boys in the Czech Republic and Slovakia and it is even more prominent among girls (Hungary, the Czech Republic, and Slovakia). There is no significant difference between the prevalence of smoking among girls in Croatia and the following countries: Bulgaria $\left(\chi^{2}=0.059\right.$; $\mathrm{p}=0.808)$, Poland $\left(\chi^{2}=1.884 ; \mathrm{p}=0.170\right)$, the Czech Republic $\left(\chi^{2}=0.810 ; p=0.368\right)$, Hungary $\left(\chi^{2}=0.387 ; p=0.534\right)$, Slovenia $\left(\chi^{2}=0.580 ; \mathrm{p}=0.446\right)$ and Slovakia $\left(\chi^{2}=0.263 ; \mathrm{p}=0.608\right)($ Table 2$)$.

\section{Lung Cancer Mortality}

According to SDRs from lung cancer in males, Croatia is ranked high 3rd place. SDR of 70.3/100,000 is higher than rates in Romania (69.5), Bulgaria (60.9), the Czech Republic (58.7),
Slovenia (57.6), and Slovakia (54.8). Only Hungary and Poland have higher rates -99.7 and 72.0, respectively. With SDR of 15.9 for females, Croatia is ranked slightly better -5 th place. Hungary (35.3), Poland (20.9), Slovenia (17.5), and the Czech Republic (16.0) have higher rates, while Romania (12.6), Slovakia (10.5), and Bulgaria (9.5) have lower rates. Male vs. female mortality ratio is the highest in Bulgaria (6.41), followed by Romania (5.52), Slovakia (5.22), Croatia (4.42), the Czech Republic (3.67), Poland (3.44), Slovenia (3.29), and Hungary (2.82) (Fig. 3).

\section{Proportion of GDP Spent on Tobacco Products}

According to the International Comparison Program (ICP) (9), the expenditure for tobacco and proportion of GDP spent on tobacco ranges from $0.8 \%$ (Romania) to $1.8 \%$ (Bulgaria, Poland, the Czech Republic and Hungary). Croatia, Slovenia and Slovakia have only slightly lower proportions: $1.6 \%, 1.5 \%$, and $1.1 \%$, respectively (data not shown).

\section{DISCUSSION AND CONCLUSIONS}

Data on tobacco consumption in Croatia reveal discouraging statistics - approximately every third male and every fifth female

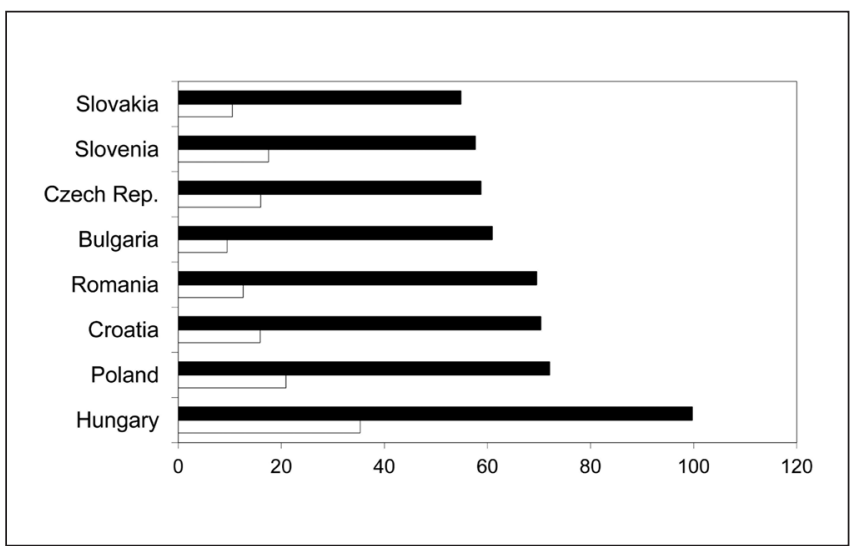

Fig 3. Standardized death rates (SDR) per 100,000 population from lung cancer in the working population (25-64 years of age) Legend: black: males; white: females

Data are standardized to the standard European population 
Table 2. The proportion of smokers among youth in Croatia and other countries (1997-2005)

\begin{tabular}{|l|c|c|c|c|}
\hline \multirow{2}{*}{} & \multicolumn{2}{|c|}{ Boys } & \multicolumn{2}{c|}{ Girls } \\
\cline { 2 - 5 } & $\mathbf{1 9 9 7 - 2 0 0 1}$ & $\mathbf{2 0 0 2 - 2 0 0 5}$ & 1997-2001 & $2002-2005$ \\
\hline Slovenia & NA & $29.50 \%$ & NA & $29.70 \%$ \\
\hline Hungary & $36.00 \%$ & $28.20 \%$ & $28.00 \%$ & $30.60 \%$ \\
\hline Czech Republic & $22.00 \%$ & $28.70 \%$ & $18.00 \%$ & $28.10 \%$ \\
\hline Slovakia & $28.00 \%$ & $31.10 \%$ & $18.00 \%$ & $17.00 \%$ \\
\hline Poland & $27.00 \%$ & $26.30 \%$ & $20.00 \%$ & $26.40 \%$ \\
\hline Bulgaria & NA & $28.70 \%$ & NA & NA \\
\hline Romania & NA & NA & NA & $24.90 \%$ \\
\hline Croatia & NA & $23.20 \%$ & & \\
\hline
\end{tabular}

smokes. During 1994-2005 the total prevalence of smoking decreased from $32.6 \%$ to $27.4 \%$. Although this decreasing trend is not statistically significant, its social importance should not be neglected. Such a decrease at the population level within a decade was primarily due to females. On the other hand, smoking among males remained almost unchanged. Additional efforts are obviously needed to reach the phase of the tobacco epidemic marked with constant decline of smoking among men and women (10, 11). In view of the overall smoking prevalence, Croatia is similar to Romania, Poland, the Czech Republic, Hungary, and Slovenia. In addition to the political past and transitional problems, these countries also share a similar burden of tobacco consumption that exceeds $20 \%$. Moreover, the analysis of smoking prevalence according to gender revealed no difference between the observed countries. Male smoking, as expected, dominates in these countries but the peak of the tobacco epidemic among women is yet to come $(12,13)$. Diminishing of sex differences already observed in Northern and Western European countries tends to spread over the continent, affecting Eastern and Southeastern Europe as well. Although female and male smoking are often reported side by side, a distinction should be made in terms of potential health consequences. Women are more susceptible to cigarette carcinogens, having higher risk of developing lung cancer and additional health risks, especially with regards to reproduction (1416). Smokers' children are affected up to adulthood, being prone to developing a variety of pathological entities, such as respiratory disease, attention deficit disorder, and cancer $(17,18)$. Smoking usually starts at a young age and, besides increasing the probability of active smoking later in life, it is associated with other severe health risks: high-risk sexual behaviour and substance abuse. Data on smoking among youth in the Tobacco Control Database were mainly extracted from two large surveys, the Health Behaviour in School-aged Children Survey (HBSC) and the Global Youth Tobacco Survey (GYTS) $(19,20)$. Consistent methodology was used in both of them, allowing greater comparability than in adult surveys (21-23). According to the 2002-2005 data, girls smoke more than boys in Slovenia, Hungary, the Czech Republic and Croatia, as opposed to Slovakia, Bulgaria, and Poland. These insignificant differences are in accordance with a study of students aged 13-15 years in seven Southeastern European countries (24) including Croatia. While current tobacco consumption among youth may be used to predict the extent of smoking among adults in the future, lung cancer mortality is the best approximation of tobacco exposure thirty years earlier. According to this mortality indicator Croatia is ranked 3rd in Europe (7). Epidemiologic analysis of lung cancer mortality trend is treated as a very predictive model of assessment of the impending tobacco epidemic - it is noteworthy that as much as $80-90 \%$ of lung cancer cases in Europe are attributable to smoking. Therefore, lung cancer mortality rates are reliable indicators of the cumulative hazard of smoking in the past (25). The relative risk of lung cancer in smokers is 20 to 30 -fold higher, suggesting a strong causal relationship. The standardized death rate (SDR) for Croatian males $(70.3 / 100,000)$ indicates that they die more often from lung cancer than males in Romania, Bulgaria, the Czech Republic, Slovenia, and Slovakia. Only Hungary and Poland have higher rates, 99.7 and 72.0. With SDR of 15.9 for females Croatia is ranked slightly better -5 th place. Hungary, Poland, Slovenia, and the Czech Republic have higher rates, while Romania, Bulgaria, and Slovakia have lower rates. SDRs for males are generally higher than for females and, as mentioned previously, this finding is consistent with the higher tobacco exposure of the male population in the past. Even so, death rates from lung cancer tend to converge in many European countries and in unfavorable circumstances become the underlying cause of the increase in female mortality. Lung cancer mortality trends in men are on a downward path in most European countries while female rates continue to rise $(26,27)$. Social changes facilitated female smoking and the tobacco industry additionally promoted this trend (28, 29). Nowadays, lung cancer mortality rates among females are rising in many EU countries (Romania, Spain, France, Slovenia, Belgium, Italy, and Finland), while they are declining among young males (30). Tobacco consumption has been recognized in Croatia as one of the major public health problems for a long period of time (31). As an EU candidate Croatia is trying to reduce tobacco consumption through the implementation and stricter enforcement of laws against smoking in public places. Furthermore, the anti-tobacco policy has become one of the major priorities in the national health agenda. Some opponents disagree with the new laws, stressing their negative economic effect disregarding the results of a relevant study (32). They simply trivialize the negative effects of smoking on the population's health and neglect the total cost of smoking which is still hard to estimate. Costs can be divided into those borne by smokers themselves and those by the rest of the community. They are comprised of tangible costs (resource costs) and intangible costs, e.g., pain, suf- 
fering and loss of life. Since smokers do not bear all costs, government taxing allocates these costs to their source of origin. In most EU countries, cigarette taxes do not represent a significant portion of the country's budget and their proportion in the total tax collection is $1-5 \%$ (Croatia $5 \%$, EC 2004). Croatia is one of the transitional countries with tax representing the highest portion of cigarettes' retail price (33). Taxing is globally considered as one of the most cost effective tobacco control options since some studies have shown that a price rise of $10 \%$ decreases consumption by about $4 \%$ in high-income countries $(34,35)$. Nevertheless, the budgetary impact of smoking can hardly be a measure of the economic impact of smoking on the community. The proportion of GDP spent on tobacco products is only a single and largely underestimated variable among tobacco-associated costs. For the selected countries it ranges from $0.8 \%$ to $1.8 \%$. The implementation of anti-tobacco measures and prevention campaigns has raised public awareness of potential tobacco-related health risks in Croatia. Although these activities are well described, the evidence of their effectiveness is insufficient. According to Goel and Budak in 2007 (11), campaigning was more than appropriate since more current and former smokers were exposed to anti-smoking campaigns in Croatia than in EU candidate and member countries. However, the percentage of smokers who wanted to quit was lower and there was a relatively low share of non-smokers claiming to be protected from second-hand smoke. Croatian antismoking campaigns faced more difficulties than similar ones in other European countries. This is because Croatia, as many transitional countries, experienced a period of increased tobacco promotion (36). Indeed, clear evidence of the effectiveness of these campaigns is still missing but a relevant effect is not to be expected since experience showed that only one smoker out of 500 gave up smoking (37). Potential effects of these campaigns on tobacco related mortality, which is the most prominent tobacco consumption indicator, should be visible only during the following decades. In the medium term, the only efficient way to reduce tobacco consumption and related mortality among all groups is individual smoking cessation. Individual interventions, such as pharmacological and behavioural therapy, are more likely to induce individual cessation efforts and significantly increase the probability of long term smoking cessation in adults. On the other hand, smoking cessation in young people requires specific approach because pharmacological and strictly behavioural measures do not seem to be so efficient in this age group. It is important to be aware of a different pattern of smoking habit among young people: a majority of them are not regular smokers. Therefore, longer term follow-ups are needed $(38,39)$. We faced several limitations and biases in our study. The Tobacco Control Database contains mainly regional surveys of country-specific data and other internationally recognized sources. These surveys use different methods and population groups to assess prevalence of tobacco consumption, which may lead to a question of compatibility. The majority of national representative studies are usually self-reported, hence there is always a possibility of under-reporting bias. Moreover, data from some countries are partially or not available, as mentioned in the results. There is always a possibility that some less visible reports and surveys exist. Despite its limitations, the Tobacco Control Database provides standardized data that can be used to track and assess tobacco consumption within and across countries. It is constantly updated and considered a relevant source of data maintained by the WHO. Nevertheless, all economic indicators regarding tobacco use in Croatia and other transitional countries should be taken with caution since a substantial portion of cigarettes is smuggled or sold on the black market because Croatia is positioned on a traditional and long-established route (40). In conclusion, huge efforts were put into anti-smoking activities during 1994-2005 in Croatia. However, during the analysed period the prevalence of adult smoking in Croatia remained relatively high and the observed decline was not statistically significant. Men do not smoke less than a decade ago and, despite the observed decline among women, new trends are observed and smoking appears to be increasing among teenage girls. These results reveal that current anti-tobacco strategies are ineffective in reducing smoking prevalence among men and youth. According to observed trends among these groups, a potential increase in the tobacco burden is expected in the future. Primary prevention has its prominent role; however, in order to limit the tobacco epidemic, Croatia has to take joint action targeting tobacco consumption per se and implementing different tobacco control measures. These activities should especially be affecting groups that are shown to be at high risk: men and youth. Comprehensive approach should include raising awareness of health risks related to tobacco consumption, restriction of smoking in public places, higher taxing of tobacco products, implementing a stricter ban on advertising and promotion of tobacco products, and supporting smoking cessation. This last measure should give results in the medium term but it needs to be supported by all health professionals. Eventually, we should expect progress at the population level in terms of social stigmatization of smoking and wider intolerance to second-hand smoking. Without doubt, we have not yet seen the full impact of smoking on the health of the population. Smoking will remain the major preventable cause of the poor public health situation in Croatia.

\section{Acknowledgement:}

We are grateful to Anamaria Lukenda for her helpful suggestions during the preparation of the manuscript.

\section{Conflict of interest statement and sponsorship:}

There is no conflict of interest related to this manuscript. Zrinka Biloglav was supported by the Croatian National Science Foundation scholarship.

\section{REFERENCES}

1. World Health Organization. Tobacco Free Initiative. Why tobacco is public health priority [Internet]. Geneva: WHO; 2009 [cited 2009 Aug 18]. Available from: http://www.who.int/tobacco/health_priority/en/ index.html.

2. Health EU. The Public Health Portal of the European Union. Tobacco [Internet]. Brussels: Health EU; 2010 [updated 2010 Apr 29; cited 2010 Aug 14]. Available from: http://ec.europa.eu/health-eu/my_lifestyle/ tobacco/index_en.htm.

3. World Health Organization. European strategy for tobacco control. Copenhagen: WHO Regional Office for Europe; 2002.

4. Joossens L, Raw M. The Tobacco Control Scale: a new scale to measure country activity. Tob Control. 2006 Jun;15(3):247-53.

5. Bala M, Strzeszynski L, Cahill K. Mass media interventions for smoking cessation in adults. Cochrane Database Syst Rev. 2008 Jan 23;(1):CD004704.

6. Thomas R, Perera R. School-based programmes for preventing smoking. Cochrane Database Syst Rev. 2006 Jul 19;3:CD001293. 
7. World Health Organization. Atlas of health in Europe. 2nd ed. Copenhagen: WHO Regional Office for Europe; 2008.

8. World Health Organization. Tobacco Control Database [Internet]. Copenhagen: WHO Regional Office for Europe; 2009 [cited 2009 Aug 17]. Available from: http://data.euro.who.int/tobacco/?TabID=2402.

9. The World Bank. The International Comparison Program [Internet]. Washington (DC): The World Bank; 2010 [cited 2010 Aug 13]. Available from: http://siteresources.worldbank.org/ICPEXT/Resources/ICP_2011. html.

10. Lopez AD, Collishaw NE, Piha T. A descriptive model of the cigarette epidemic in developed countries. Tob Control. 1994;3(3):242-7.

11. Goel RK, Budak J. Smoking patterns in Croatia and comparisons with European nations. Cent Eur J Public Health. 2007 Sep;15(3):110-5.

12. Kovacić L, Gazdek D, Samardzić S. Croatian health survey: cigarette smoking. Acta Med Croatica. 2007 Jun;61(3):281-5. (In Croatian.)

13. Boyle P. Cancer, cigarette smoking and premature death in Europe: a review including the Recommendations of European Cancer Experts Consensus Meeting, Helsinki, October 1996. Lung Cancer. 1997 May; 17(1):1-60.

14. Teixeira E, Conde S, Alves P, Ferreira L, Figueiredo A, Parente B. Lung cancer and women. Rev Port Pneumol. 2003 May-Jun;9(3):225-47. (In Portuguese.)

15. Olson JE, Yang P, Schmitz K, Vierkant RA, Cerhan JR, Sellers TA. Differential association of body mass index and fat distribution with three major histologic types of lung cancer: evidence from a cohort of older women. Am J Epidemiol. 2002 Oct 1;156(7):606-15.

16. Schneider S, Huy C, Schütz J, Diehl K. Smoking cessation during pregnancy: a systematic literature review. Drug Alcohol Rev. 2010 Jan;29(1):81-90.

17. Einarson A, Riordan S. Smoking in pregnancy and lactation: a review of risks and cessation strategies. Eur J Clin Pharmacol. 2009 Apr;65(4):32530.

18. Rogers JM. Tobacco and pregnancy. Reprod Toxicol. 2009 Sep;28(2):15260

19. Warren CW, Jones NR, Peruga A, Chauvin J, Baptiste JP, Costa de Silva $\mathrm{V}$, et al; Centers for Disease Control and Prevention (CDC). Global youth tobacco surveillance, 2000-2007. MMWR Surveill Summ. 2008 Jan 25;57(1):1-28.

20. Currie C, Nic Gabhainn S, Godeau E; International HBSC Network Coordinating Committee. The Health Behaviour in School-aged Children: WHO Collaborative Cross-National (HBSC) study: origins, concept, history and development 1982-2008. Int J Public Health. 2009 Sep;54 Suppl 2:131-9.

21. Bezinović P, Malatestinić D. Perceived exposure to substance use and risk-taking behavior in early adolescence: cross-sectional study. Croat Med J. 2009 Apr;50(2):157-64.

22. Kuzman M, Simetin IP, Franelić IP. Early sexual intercourse and risk factors in Croatian adolescents. Coll Antropol. 2007 Apr;31 Suppl 2:121-30.

23. Guilamo-Ramos V, Litardo HA, Jaccard J. Prevention programs for reducing adolescent problem behaviors: Implications of the co-occurrence of problem behaviors in adolescence. J Adolesc Health. 2005 Jan;36(1):82-6.
24. Stojiljkovic D, Haralanova M, Nikogosian H, Petrea I, Chauvin J, Warren $\mathrm{CW}$, et al. Prevalence of tobacco use among students aged 13-15 years in the South-Eastern Europe health network. Am J Health Behav. 2008 Jul-Aug;32(4):438-45.

25. Bray FI, Weiderpass E. Lung cancer mortality trends in 36 European countries: secular trends and birth cohort patterns by sex and region 1970-2007. Int J Cancer. 2010 Mar 15;126(6):1454-66.

26. Bosetti C, Levi F, Lucchini F, Negri E, La Vecchia C. Lung cancer mortality in European women: recent trends and perspectives. Ann Oncol. 2005 Oct;16(10):1597-604.

27. Ferlay J, Autier P, Boniol M, Heanue M, Colombet M, Boyle P. Estimates of the cancer incidence and mortality in Europe in 2006. Ann Oncol. 2007 Mar; 18(3):581-92.

28. Tinkler P. Rebellion, modernity, and romance: smoking as a gendered practice in popular young women's magazines, Britain 1918-1939. Womens Stud Int Forum. 2001;24(1):111-22.

29. Ernster V, Kaufman N, Nichter M, Samet J, Yoon SY. Women and tobacco: moving from policy to action. Bull World Health Organ. 2000;78(7):891901

30. Zatonski WA, Manczuk M, Powles J, Negri E. Convergence of male and female lung cancer mortality at younger ages in the European Union and Russia. Eur J Public Health. 2007 Oct;17(5):450-4.

31. Loubeau PR. Selected aspects of tobacco control in Croatia. Cent Eur J Public Health. 2009 Mar; 17(1):47-52.

32. Jha P, Chaloupka FJ. The economics of global tobacco control. BMJ. 2000 Aug 5;321(7257):358-61.

33. Szilagyi T. Tobacco control in Hungary: past, present, future. Budapest (Hungary): Health 21 Hungarian Foundation; 2004.

34. Jha P, Chaloupka F. Curbing the epidemic: governments and the economics of tobacco control. Washington (DC): The World Bank; 1999.

35. Joossens L, Raw M. Progress in combating cigarette smuggling: controlling the supply chain. Tob Control. 2008 Dec;17(6):399-404.

36. Simpson D. Croatia: hot salaries, cool penguins. Tob Control. 1999;8(4):362.

37. Hey K, Perera R. Quit and Win contests for smoking cessation. Cochrane Database Syst Rev. 2005 Apr 18;(2):CD004986. Review. Update in: Cochrane Database Syst Rev. 2008;(4):CD004986.

38. Grimshaw GM, Stanton A. Tobacco cessation interventions for young people. Cochrane Database Syst Rev. 2006 Oct 18;(4):CD003289.

39. Sussman S, Sun P, Dent CW. A meta-analysis of teen cigarette smoking cessation. Health Psychol. 2006 Sep;25(5):549-57.

40. Joossens L, Raw M. Cigarette smuggling in Europe: who really benefits? Tob Control. 1998;7(1):66-71.

Received June 28, 2011

Accepted in revised form January 10, 2012 